\title{
Vasoplegia in sepsis depends on the vascular system, vasopressor, and time-point: a comparative evaluation in vessels from rats subjected to the cecal ligation puncture model
}

\begin{tabular}{|r|l|}
\hline Journal: & Canadian Journal of Physiology and Pharmacology \\
\hline Manuscript ID & cjpp-2015-0514.R2 \\
\hline Danuscript Type: & Article \\
\hline Complete List of Authors: & $\begin{array}{l}\text { Bernardelli, Angélica; Universidade Federal do Paraná, Pharmacology } \\
\text { da Silva, Rita; Universidade Federal do Paraná, Pharmacology } \\
\text { Corrêa, Thiago; Universidade Federal de Santa Catarina, Pharmacology } \\
\text { da Silva-Santos, José Eduardo; Universidade Federal de Santa Catarina, } \\
\text { Pharmacology }\end{array}$ \\
\hline Keyword: & $\begin{array}{l}\text { cecal ligation and puncture, hyperresponsiveness, hyporeactivity, septic } \\
\text { shock, vascular dysfunction }\end{array}$ \\
\hline \multicolumn{2}{|c}{} \\
\hline
\end{tabular}


Vasoplegia in sepsis depends on the vascular system, vasopressor, and time-point: a comparative evaluation in vessels from rats subjected to the cecal ligation puncture model

Angélica K. Bernardelli ${ }^{1,2}$, Rita de C. V.de A.F. Da Silva ${ }^{1,2}$, Thiago Corrêa ${ }^{2}$, and José Eduardo Da Silva-Santos ${ }^{2 *}$

\footnotetext{
${ }^{1}$ Department of Pharmacology, Universidade Federal do Paraná, Curitiba, PR, Brazil;

${ }^{2}$ Laboratory of Cardiovascular Biology, Department of Pharmacology, Universidade Federal de Santa Catarina, Florianópolis, SC, Brazil.
}

*Corresponding author: Department of Pharmacology, Room 116, Universidade Federal de Santa Catarina, Campus Universitário, Trindade - Florianópolis, SC, 88.040-900, Brazil Tel: +55 (48) 3721-4847

E-mail: j.e.silva.santos@ufsc.br 


\begin{abstract}
We evaluated the effects of phenylephrine, norepinephrine, angiotensin II and vasopressin in mesenteric, renal, carotid and tail arteries, and in perfused mesenteric vascular bed from rats subjected to the cecal ligation and puncture (CLP) model of sepsis. Phenylephrine and angiotensin II were less efficacious in mesenteric arteries from the CLP $6 \mathrm{~h}$ and CLP $18 \mathrm{~h}$ groups than in preparations from non-septic animals, but no differences were found for norepinephrine and vasopressin between the preparations. In renal arteries, none of the vasoconstrictors had impaired activity in the CLP groups. Nonetheless, carotid arteries from the CLP $18 \mathrm{~h}$ group presented reduced reactivity to all vasoconstrictors tested, but only phenylephrine and norepinephrine had their effects reduced in carotid arteries from the CLP $6 \mathrm{~h}$ group. Despite the reduced responsiveness to phenylephrine, tail arteries from septic rats were hyperreactive to vasopressin and norepinephrine at $6 \mathrm{~h}$ and $18 \mathrm{~h}$ after the CLP surgery, respectively. The mesenteric vascular bed from CLP groups was hyporeactive to phenylephrine, norepinephrine and angiotensin II, but not to vasopressin. The vascular contractility in sepsis varies from the well-described refractoriness, to unaltered or even hyperresponsiveness to vasoconstrictors, depending on the vessel, the vasoactive agent, and the time period evaluated.
\end{abstract}

Key words: cecal ligation and puncture, hyperresponsiveness, hyporeactivity, septic shock, tone, vascular dysfunction, vasoconstrictors. 


\section{Introduction}

Sepsis-induced hypotension is caused by the inability of vessels to keep their tone, leading to reduced peripheral vascular resistance. This continuous low blood pressure results in tissue hypoperfusion and contributes, at least in part, to the development of multiple organ failure and to the high mortality rates associated with severe sepsis and septic shock. Clinical strategies recommended by the International Guidelines for Management of Severe Sepsis and Septic Shock to elevate blood pressure include aggressive fluid resuscitation with crystalloids (30 mL/kg) and administration of vasopressor agents (Dellinger et al. 2013). Importantly, patients with septic shock usually develop refractory hypotension to fluid and vasoconstrictors, which is also associated with vascular dysfunction. Indeed, vascular hyporeactivity to vasoconstrictors, or vasoplegia, is one of the main clinical characteristics of septic shock (Landry and Oliver 2001). To circumvent this vascular refractoriness and effectively manage the hypotension, patients with septic shock are often subjected to very high doses and continuous administration of vasoactive drugs.

A wide array of experimental studies, dating from the 1960s, have been conducted to investigate the hemodynamic characteristics of sepsis, resulting in seminal discoveries regarding the functional and molecular changes that account for the vascular dysfunction in sepsis (for review see Kimmoun et al. 2013). Nonetheless, such studies do not provide enough evidence to indicate the use of a particular vasoactive agent in sepsis. Thus, the vasopressor therapy used in septic patients remains based mainly in clinical experience and deficient experimental data (Dellinger et al. 2013; Ellender and Skinner 2008).

In spite of the systemic and severe hypotension that occurs in septic shock, several laboratory investigations using either in vivo or in vitro experimental models of sepsis revealed that vasoplegia does not occur in all kinds of vessels (e.g. Cameron et al. 1998; Li et al. 1992; Martin et al. 1993; Suba et al. 1992). However, to our knowledge, these and other studies 
focused on this field were either restricted to specific time periods post induction of sepsis or did not explore vascular reactivity to the vasoactive agents commonly used in septic patients. In addition, the profile of vascular reactivity changes in response to some endogenous vasoactive agents, such as angiotensin II, remains to be investigated. Importantly, norepinephrine has been described as the first-choice vasopressor in sepsis, but other agents such as vasopressin and phenylephrine are still recommended when norepinephrine fails or generates deleterious effects (Dellinger et al. 2013).

Taking into account i) the lack of knowledge regarding the deleterious or beneficial effects of vasoactive drugs in sepsis, ii) the limited possibilities for evaluation of the vascular responsiveness to vasoactive agents in humans with sepsis, and iii) the incomplete understanding regarding the behaviour of arteries in terms of their sensitivity to endogenous and clinically used vasopressors, this study was designed to explore and compare the contractile responses generated in vessels during the onset and later stages of polymicrobial sepsis induced by the cecal ligation and puncture (CLP) model of sepsis.

\section{Materials and methods}

\section{Animals}

Male Wistar rats (3 and 4 months old) were supplied by the Universidade Federal de Santa Catarina. The animals were maintained under controlled laboratory conditions $(12 / 12 \mathrm{~h}$ light/dark cycle; $22 \pm 2{ }^{\circ} \mathrm{C}$; unrestricted access to water and chow) before and during the entire period of experiments. All procedures and protocols described in this study were conducted in accordance with Brazilian and international guidelines for research using laboratory animals, and were previously approved by the Institutional Ethics Committee of Universidade Federal do Paraná (authorization number 23075.005994/2014-96). 


\section{Cecal ligation and puncture (CLP) surgery}

The CLP surgery was conducted as previously described (Rittirsch et al. 2009), with the following minor modifications. Before the induction of anaesthesia, the animals received 5 $\mathrm{mg} / \mathrm{kg}$ xylazine and $10 \mathrm{mg} / \mathrm{kg}$ tramadol (given by the intraperitoneal route, i.p.) to achieve presurgical sedation and post-surgical analgesia, respectively. Five minutes after this treatment, the animals were placed in an anaesthetic chamber saturated with 5\% isoflurane in $100 \%$ oxygen. Immediately after induction of anaesthesia, the animals were removed from the anaesthetic chamber and maintained under inhalant anaesthesia (3\% isoflurane) delivered by facemask. After confirming the absence of reactions to pinch stimuli in the limbs, tail and abdomen, 200 $\mu \mathrm{L}$ lidocaine ( $2 \%$, without a vasoconstrictor) was injected in the abdominal muscle and skin (closed to the linea alba), and an incision (approximately $1 \mathrm{~cm}$ ) was made in the abdomen allowing the exteriorization of the cecum. We used suture lines to cause a partial obstruction in the cecum, distal to the ileocecal valve (comprising 50\%), and four non-transfixing holes were made with a 18-gauge needle in the cecum, followed by careful compression to release the intestinal contents into the abdominal cavity. The cecum was positioned inside the peritoneum, the abdominal muscle was sutured, and the skin was closed with wound clips (AutoClip ${ }^{\circledR}$, MikRon Precision, Inc., Gardena, CA, USA). After the surgery, all animals were subjected to fluid replacement (sterile isotonic saline, $30 \mathrm{~mL} / \mathrm{kg}$, s.c.), and were maintained in warmed cages until they had completely recovered from anaesthesia. This protocol resulted in a $40 \%$ mortality in our experiments, with deaths occurring mainly between $24 \mathrm{~h}$ and $36 \mathrm{~h}$ after the CLP surgery (Supplementary Fig. S1). The CLP-subjected rats were divided into two separate groups, which were used for isolation of vascular preparations at $6 \mathrm{~h}$ (CLP $6 \mathrm{~h}$ group) or $18 \mathrm{~h}$ (CLP $18 \mathrm{~h}$ group) after the surgery. The animals used in the CLP $18 \mathrm{~h}$ group received an additional dose of tramadol (10 mg/kg, s.c.) $12 \mathrm{~h}$ after the CLP surgery. Arteries from sham-operated rats 
(subjected to the same procedures as the CLP groups, except for the ligature and perforation of cecum) displayed unaltered in vitro vascular reactivity to vasoconstrictors and $\mathrm{KCl}$ at both 6 and $18 \mathrm{~h}$ after the surgery as did vessels obtained from naïve animals (Supplementary Fig. S2; de Souza et al. 2015). For this reason, naïve animals were used in the control (sham, non-septic) groups in our experiments.

\section{Isolated vascular preparations and assessment of vascular reactivity}

Vessels were isolated under general anaesthesia induced by intraperitoneal injection of ketamine/xylazine (100/20 mg/kg, i.p.). After confirming the absence of reactions to pinch stimuli in the limbs, tail and abdomen, the superior mesenteric artery, the left and right carotid and renal arteries, and the tail artery, were carefully dissected and removed from the animals, which were euthanized by exsanguination during this process. The vessels were immediately placed in Petri-dishes containing cold $\left(\sim 4^{\circ} \mathrm{C}\right)$ physiological nutritive solution (PSS, composition in mmol/L: $\mathrm{NaCl} 131.3, \mathrm{KCl} 4.7, \mathrm{KH}_{2} \mathrm{PO}_{4} 1.18, \mathrm{MgSO}_{4} 7 \mathrm{H}_{2} \mathrm{O} 1.17, \mathrm{NaHCO}_{3} 14.9$, D-glucose 5.5, $\mathrm{CaCl}_{2} 2 \mathrm{H}_{2} \mathrm{O}$ 1.6, EDTA 0.08). The arteries were cleaned from all connective tissues and cut into rings $(2 \mathrm{~mm})$. The rings were mounted in tissue organ baths (Model EZNeWMyo-4TB ${ }^{\text {TM }}$ with i-FOT 50SW force transducers, coupled to BRAM-4B bridge amplifier, all from GlobalTown Microtech, Inc., Sarasota, FL, USA) containing warmed PSS $\left(37^{\circ} \mathrm{C}\right)$ continuously bubbled with $95 \% \mathrm{O}_{2} / 5 \% \mathrm{CO}_{2}$. The vascular tone and reactivity to vasoactive agents were recorded using computer-connected data acquisition hardware and the corresponding acquisition software (PowerLab $4 / 30^{\circledR}$ and LabChart ${ }^{\circledR}$ Pro v. 7.3.3, respectively, both from AD Instruments, Australia).

In our experiments, the preparations were kept under a basal tension of $0.5 \mathrm{~g}$ (mesenteric, renal and tail arteries), or $1.0 \mathrm{~g}$ (carotid arteries). After the system setup was complete, a $60 \mathrm{~min}$ interval was allowed for stabilization. During each resting period in our protocol, the PSS was 
replaced every $15 \mathrm{~min}$. After stabilization, the vessels were exposed to high $\mathrm{KCl}(120 \mathrm{mmol} / \mathrm{L})$ modified PSS for 10-15 min, and the maximum contractile responses were recorded. The preparations were washed with regular PSS, and after a further interval of $30 \mathrm{~min}, 1 \mu \mathrm{mol} / \mathrm{L}$ phenylephrine was added into the baths. Under the sustained contraction induced by phenylephrine, the preparations were exposed to acetylcholine $(1 \mu \mathrm{mol} / \mathrm{L})$. Only those vessels that reached a relaxation greater than or equal to $80 \%$ in response to acetylcholine were considered functional endothelium and were used in this study.

After the verification of the integrity of the endothelium, the arteries were subjected to a new stabilization period of $60 \mathrm{~min}$ (carotid arteries), or $30 \mathrm{~min}$ (mesenteric, renal, and tail arteries), which was followed by the addition of cumulative concentrations of phenylephrine, norepinephrine, angiotensin II, or vasopressin, in a range between $1 \mathrm{nmol} / \mathrm{L}$ and $30 \mu \mathrm{mol} / \mathrm{L}$. The changes in vascular tone recorded in vessels obtained from CLP $6 \mathrm{~h}$ and CLP $18 \mathrm{~h}$ groups were compared with the responses from preparations obtained from control (non-septic) animals.

\section{Assessment of vascular reactivity in the perfused mesenteric vascular bed}

The mesenteric vascular bed was removed from rats under deep anesthesia induced by intraperitoneal injection of ketamine/xylazine (100/20 mg/kg, i.p.), and prepared for perfusion as previously described (McGregor 1965). Briefly, after confirming the absence of reactions to pinch stimuli in the limbs, tail and abdomen, the abdomen was opened and a catheter was inserted into the superior mesenteric artery, allowing the immediate administration of heparin (100 IU) diluted in PSS to avoid blood clotting. The entire intestine was removed from the abdominal cavity, and the mesenteric vascular bed was perfused with $20 \mathrm{~mL}$ of warmed PSS (37 $\left.{ }^{\circ} \mathrm{C}\right)$ to remove blood. The animals were euthanized by bilateral pneumothorax and exsanguination immediately after the removal of the intestine. In our experiments, only the four main arterial branches from the superior mesenteric trunk running to the terminal ileum were 
maintained opened for perfusion, and all other branches were tied off. The vascular bed was separated from intestine and accommodated in a 50-mL chamber perfusion apparatus connected to a pressure transducer coupled to a computerized data acquisition system and its application software (PowerLab 4/30 ${ }^{\circledR}$ and LabChart ${ }^{\circledR}$ Pro v. 7.3.3, respectively, both from AD Instruments, Australia). The preparations were continuously perfused with $4 \mathrm{~mL} / \mathrm{min}$ PSS at $37^{\circ} \mathrm{C}$, previously bubbled with $95 \% \mathrm{O}_{2} / 5 \% \mathrm{CO}_{2}$. A stabilization period of 30 min was allowed and 30 nmol phenylephrine was injected into the perfusion apparatus. The ability of phenylephrine to increase the perfusion pressure (in $\mathrm{mm} \mathrm{Hg}$ ) was used as indicative of the correct set-up of the mesenteric vascular bed.

After an additional interval of $15 \mathrm{~min}$, preparations removed from control, CLP $6 \mathrm{~h}$ and CLP $18 \mathrm{~h}$ groups were exposed to non-cumulative doses of phenylephrine, norepinephrine (both at 10, 30 and $100 \mathrm{nmol})$, vasopressin (3, 10 and $30 \mathrm{pmol})$, or angiotensin II (30 and $100 \mathrm{nmol})$. Only two vasoactive agents were randomly tested per preparation. To allow the return of the vascular perfusion pressure to baseline values there was an interval of 10-15 min between each administration of the same agent, and 30 min between different vasoactive agents. The changes in vascular perfusion pressure recorded in mesenteric vascular beds obtained from CLP $6 \mathrm{~h}$ and CLP $18 \mathrm{~h}$ groups were compared with the responses from preparations obtained from control (non-septic) animals.

\section{Drugs and reagents}

Phenylephrine hydrochloride, D-norepinephrine D-bitartrate, arginine-vasopressin, angiotensin II and all salts used to prepare the physiological nutritive solution (PSS) were purchased from Sigma-Aldrich (Saint Louis, MO, USA). Isoflurane, lidocaine hydrochloride (without vasoconstrictor) and tramadol hydrochloride were obtained from Cristália (Itapira, São 
Paulo, Brazil). Xylazine and ketamine were from Syntec do Brasil Ltda (Cotia, São Paulo, Brazil).

\section{Statistical analysis}

The results ( $n=5-9$ preparations for each experimental group) were expressed as the mean \pm standard error of the mean. Statistical analysis was performed using one-way analysis of variance (ANOVA) followed by Tukey's multiple comparison test. A $p$ value less than 0.05 was considered statistically significant. The graphs were drawn and the statistical analyses were performed using GraphPad Prism version 6.0g (GraphPad Software, La Jolla, CA, USA).

\section{Results}

\section{Influence of CLP-induced sepsis on the contractile responses of rat mesenteric artery}

The exposure of superior mesenteric arteries from control (non-septic) animals to cumulative concentrations of phenylephrine, norepinephrine, angiotensin II or vasopressin resulted in a concentration-dependent increase in the vascular tone (Fig. 2A-D, open circles). Angiotensin II was the least efficacious of the vasoconstrictors tested in our experiments, but the analysis of the half maximal effective concentration $\left(\mathrm{EC}_{50}\right)$ revealed that this peptide was the most potent vasoactive agent in mesenteric arteries from control animals, followed by vasopressin (Table 1). In spite of the lack of changes in the contractile responses to $\mathrm{KCl}$ (Fig. 1A), the superior mesenteric arteries obtained from the CLP $6 \mathrm{~h}$ and CLP $18 \mathrm{~h}$ groups presented depressed maximal responses, as well as increased $\mathrm{EC}_{50}$ values, to both phenylephrine and angiotensin II (Figs. 2A and C; Table 1). In contrast, the maximum contractile effect $\left(\mathrm{E}_{\max }\right)$ of norepinephrine (Fig. 2B) and vasopressin (Fig. 2D) remained unaltered in mesenteric arteries obtained from septic animals. 


\section{Unaltered reactivity of the renal artery from CLP-subjected rats to vasoconstrictors}

Renal arteries obtained from control (non-septic) rats showed reduced maximal contractile responses to angiotensin II $\left(\mathrm{E}_{\max }=0.22 \pm 0.8 \mathrm{~g}\right)$, compared with the other vasoconstrictors used in our experiments. Indeed, phenylephrine, norepinephrine and vasopressin, presented a similar profile for both efficacy and potency when evaluated for their ability to induce concentration-dependent augmentation of the vascular tone of the renal arteries (Fig. 3, open circles; Table 2). Importantly, our experiments revealed that renal arteries removed from the CLP $6 \mathrm{~h}$ or the CLP $18 \mathrm{~h}$ groups did not show any impairment in the vascular reactivity to $\mathrm{KCl}$ (Fig. 1B), or to the vasoactive agents tested in this study (Fig. 3; Table 2).

\section{Reduced contractile responses of carotid arteries from rats subjected to CLP}

Carotid arteries from control (non-septic) animals displayed a similar profile of responses to all vasoconstrictors tested (Fig. 4, open circles), although vasopressin was significantly less efficacious (lower $\mathrm{E}_{\max }$ ) and less potent (greater $\mathrm{EC}_{50}$ ) than were phenylephrine, norepinephrine and angiotensin II (Table 3). Despite the fact that responses to $\mathrm{KCl}$ were not different among the groups (Fig. 1C), in vitro preparations of carotid arteries taken from the CLP $18 \mathrm{~h}$ group (Fig. 4, closed squares) presented reduced reactivity to all vasoconstrictors used in this study, compared with control vessels. In addition, both phenylephrine and norepinephrine, but not angiotensin II or vasopressin, had a diminished ability to increase the carotid tone in the CLP $6 \mathrm{~h}$ group (Figs. 4A-D, closed circles).

\section{Influence of CLP-induced sepsis on the contractile responses of rat tail artery}

Tail arteries from non-septic rats showed remarkable contractile responses to phenylephrine and norepinephrine (Figs. 5A and B, respectively; open circles), but were less responsive to angiotensin II and vasopressin (Figs. 5C and D, respectively; open circles). 
Interestingly, in spite of the reduced reactivity to phenylephrine recorded in tail arteries from both the CLP $6 \mathrm{~h}$ and CLP $18 \mathrm{~h}$ groups (Fig. 5A, closed symbols), we found enhanced responses to norepinephrine (Fig. 5B) and vasopressin (Fig. 5D) in the tail artery from CLP $18 \mathrm{~h}$ and CLP $6 \mathrm{~h}$ groups, respectively, compared with the responses recorded in the tail arteries obtained from control animals. The enhanced $\mathrm{E}_{\max }$ was not accompanied by any change in the $\mathrm{EC}_{50}$ for norepinephrine or vasopressin (Table 4). In addition, both KCl- and angiotensin II-induced constriction remained unchanged in the tail artery isolated from animals subjected to CLP (Figs. $1 \mathrm{D}$ and $5 \mathrm{C}$, respectively).

\section{Influence of CLP-induced sepsis on the reactivity of the mesenteric vascular bed}

Administration of vasoconstrictors into the perfusion apparatus resulted in a dosedependent increase in the perfusion pressure of the mesenteric vascular bed obtained from control animals, as showed by the peak of effect in the perfusion pressure (Fig. 6, open bars), and the area under the curve from each dose administered, an indicative of the duration of the effects (Supplementary Fig. S3, open bars). The perfused mesenteric vascular beds obtained from the CLP $6 \mathrm{~h}$ and CLP $18 \mathrm{~h}$ groups showed a similar pattern of reduced reactivity to phenylephrine and norepinephrine (Figs. 6A and B, respectively), compared with control. This hyporeactivity was also found after administration of $100 \mathrm{nmol}$ angiotensin II in both the CLP groups (Fig. 6C). As revealed by the analysis of the area under the curve of responses to phenylephrine, norepinephrine and angiotensin II, the CLP surgery also reduced the duration of the effects of these vasoactive agents (Supplementary Fig. S3A, B and C, respectively). However, the peak of the effects of vasopressin was not reduced in the CLP $6 \mathrm{~h}$ and CLP $18 \mathrm{~h}$ groups, compared with control (Fig. 6D). Indeed, the intermediary dose of vasopressin used in our experiments showed enhanced effects in the mesenteric vascular bed from the CLP $18 \mathrm{~h}$ group (Fig. 6D, $10 \mathrm{pmol}$ ). In addition, the duration of the responses to $30 \mathrm{pmol}$ vasopressin were 
augmented in the CLP $6 \mathrm{~h}$ and CLP $18 \mathrm{~h}$ groups, compared with control, as revealed by the area under the curve of its effects (Supplementary Fig. S3D).

\section{Discussion}

The behavior of the vascular system during the progression of sepsis remains poorly investigated. In this study, we evaluated the effects of the exogenously administered or endogenously produced vasoactive agents phenylephrine, norepinephrine, vasopressin and angiotensin II in different arteries (superior mesenteric, renal, carotid and tail), and in the mesenteric vascular bed of rats subjected to CLP-induced sepsis.

The results described in this study clearly demonstrate that the impaired vascular reactivity of mesenteric arteries from the CLP $6 \mathrm{~h}$ and CLP $18 \mathrm{~h}$ groups includes reduced responses to phenylephrine and angiotensin II, but not to norepinephrine and vasopressin, while the renal arteries obtained from the same CLP groups did not present any significant impairment in their responsiveness to vasoconstrictors. A number of studies with different experimental models of sepsis have demonstrated that vital organs such as the intestine and kidneys may present either reduced or improved blood flow depending on the vasoconstrictor administered, the experimental model, or the period of sepsis evaluated (Bennett et al. 2004; Hiltebrand et al. 2007; Krejci et al. 2006; Revelly et al. 2000). Importantly, the CLP surgery performed in our experiments resulted in a lethality rate around $40 \%$ (Fig. S1), and a sustained reduction in systemic blood pressure (Supplementary Table S1), even after receiving fluid replacement. Thus, one of the main findings of this study is the demonstration that there are remarkable differences in the development of contractile dysfunction among vessels from rats subjected to the CLP model of sepsis, which occur even in the presence of systemic hypotension. Notably, these differences may contribute to deleterious effects of vasopressor therapy on both blood flow and function of intestinal tract and kidneys during the septic state. 
We also explored the profile of responses of carotid arteries from CLP-subjected animals to vasoconstrictors. To our knowledge, the few studies that have investigated the effects of sepsis on the in vitro responses of carotid arteries have been restricted to approaches using endotoxemic animals (Arden et al. 1994; Gunnett et al. 1999). Our findings confirmed the development of vascular dysfunction in the carotid artery from rats subjected to CLP-induced sepsis. In addition, our results also revealed that in contrast to renal arteries (that did not present any impairment in their contractile responses), or mesenteric arteries (in which the loss in reactivity was dependent on the agonist used), carotid arteries appear to develop a more comprehensive hyporeactivity to vasoconstrictors. Indeed, all agents tested in our experiments including vasopressin, which has been shown to increase the blood pressure in patients with septic shock who present refractoriness to norepinephrine (Holmes et al. 2001; Tsuneyoshi et al. 2001) - had reduced efficacy in carotids arteries obtained from animals subjected to CLP. Importantly, changes in the carotid tone may have a direct effect on the internal carotid blood flow and, consequently, on the cerebral blood flow (Meyer et al. 1967). Indeed, human patients with sepsis may present reduced cerebral blood flow (Bowton et al. 1989; Papadopoulos et al. 2000), reinforcing the need for better comprehension regarding the reactivity of carotid arteries to endogenous vasoconstrictors, as well as to administered vasopressors, during the septic state.

The significance of changes in the renin-angiotensin system to vascular function in sepsis remains poorly investigated, despite of the previous studies addressing the role of circulating renin, angiotensin-converting enzyme and angiotensin II (Doerschug et al. 2010; Hilgenfeldt et al. 1987; Isakson et al. 1977; Schaller et al. 1985; Zhang et al. 2014). Curiously, there are only a few studies exploring the reactivity to angiotensin II in vascular preparations obtained from animals subjected to experimental models of sepsis (Cameron et al. 1998; de Souza et al. 2015; Mastrangelo et al. 2000). Indeed, at least to our knowledge, this is the first study comparing the contractile effects of angiotensin II among different vessels in the CLP 
model of sepsis, and our data clearly demonstrate that both mesenteric and carotid arteries from CLP-subjected rats, as well as the mesenteric vascular bed, but not renal and tail arteries, display reduced reactivity to angiotensin II. Taking into account the physiological role of angiotensin II on the regulation of vascular tone and blood pressure (for review see Paul et al. 2006), and recognizing that during septic insult the effects of angiotensin II on the vascular tone are reduced, but only in parts of the vascular system, may facilitate a better understanding of the importance and risks of pharmacological strategies involving either activation or inhibition of the renin-angiotensin system in the treatment of septic shock.

Hypotension and low tissue blood flow in sepsis are putatively associated with the inability of the vasculature to regularly maintain tone in response to endogenous or administered vasoactive agents. However, we found that in spite of the reduced responsiveness to phenylephrine, tail arteries obtained from septic rats showed increased contractile responses to norepinephrine and vasopressin at $18 \mathrm{~h}$ and $6 \mathrm{~h}$ after the CLP surgery, respectively. Although the rat tail artery cannot be directly compared with any vessel found in humans, a number of in vitro studies have been conducted with this vessel mainly to explore the vascular biology in arteries with reduced diameter, when compared with classical vascular preparations (i.e. aortic rings). Taking into account our findings in CLP-subjected rats, it is reasonable to speculate that in spite of the vascular failure that takes place during the septic insult, some vessels may present augmented responses to vasopressor agents, including, but not restricted to norepinephrine and vasopressin.

Despite the demonstration that changes in the contractile responses of superior mesenteric, renal, carotid and tail arteries from rats in the CLP model of sepsis depend on the vasopressor, time-point ( $6 \mathrm{~h}$ or $18 \mathrm{~h}$ after the CLP surgery) and vessel evaluated, it is important to mention that these arteries are large conductance arteries, with minor influence mainly in the acute control of blood pressure. As an attempt to bypass at least part of this limitation of our 
study, we also evaluated the effects of phenylephrine, norepinephrine, vasopressin and angiotensin II in the perfused mesenteric vascular bed from CLP-subjected rats. The data obtained revealed that also in this vascular preparation, which comprises mainly small resistance arteries, there are remarkable differences in the reactivity to different vasoactive agents. In addition, the comparison also showed that sepsis-induced changes in the reactivity of large conductance and small resistance arteries from the same vascular bed does not follow a rigorous pattern, in spite of the similarities found. For instance, both the superior mesenteric arteries and the mesenteric vascular beds from the CLP $6 \mathrm{~h}$ and CLP $18 \mathrm{~h}$ groups were hyporeactive to phenylephrine and angiotensin II, and presented unchanged or even enhanced responses to vasopressin. However, the reactivity to norepinephrine was significantly reduced in the mesenteric vascular bed, but not in the superior mesenteric arteries from CLP-subjected animals. Importantly, since the differences found in the vascular reactivity of large and small mesenteric arteries cannot be applied for all vascular beds, additional studies must be performed to clarify how each regional vascular system (i.e. renal vascular bed and brain vascular bed, among others) reacts to vasoactive agents during the septic insult, as well as their role in sepsis-induced hypotension.

A number of events, including but not limited to overproduction of nitric oxide (Fernandes and Assreuy 2008), deregulation of the redox state and down-regulation of membrane receptors (Takakura et al. 2003), opening of $\mathrm{K}^{+}$channels (da Silva-Santos et al. 2002), and activation of metalloproteinases (de Souza et al. 2015), have been associated with the vascular dysfunction in sepsis. Our study did not address which cellular mechanisms are responsible for the profile of differences in the changes of reactivity of a single vessel to different vasoactive agents, nor for the differences in the effects of the same vasoactive agent in different vessels. Moreover, the experiments performed in our study also did not explore whether the reduced reactivity to all vasoconstrictors evaluated, as found in carotid arteries, or 
the unchanged or enhanced responses found for specific vasoactive agents in different preparations (i.e. vasopressin in the renal artery, as well as in the mesenteric vascular bed), are detrimental or beneficial in terms of maintenance of blood supply, or development of organ dysfunction during a septic state. Additional experiments to assess intracellular pathways and microcirculation, using molecular and in vivo approaches, respectively, must be carried out to allow any speculation regarding the aforementioned limitations of our study.

Finally, we conclude that the impaired vascular function may vary from the widely described refractoriness, to unaltered or even hyperresponsiveness to vasoconstrictors, depending on the vessel, the vasoactive agent, or the time period evaluated. Better knowledge regarding this differential behavior of vessels in response to vasopressor agents, including the endogenously produced norepinephrine, angiotensin II, and vasopressin, as well as the relevance of such differences in sepsis-associated organ dysfunction may provide new insights in the management of cardiovascular dysfunction in sepsis.

\section{Acknowledgements}

This work was fully supported by grants from the Fundação de Amparo à Pesquisa e Inovação do Estado de Santa Catarina (FAPESC, Brazil, TR2012000367 and TR201200078) and Conselho Nacional de Desenvolvimento Científico e Tecnológico (CNPq, Brazil; 448738/2014). The authors declare that they have no conflicts of interest.

\section{References}

Arden, W.A., Fiscus, R.R., Wang, X., Maley, R., Lanzo, S., and Gross, D.R. 1994. Early endotoxic shock results in enhanced vasodilator responses to nitroglycerin but unaltered 
responses to neuropeptides calcitonin gene-related peptide and substance P. Shock, 1(6): 425431. doi: 10.1097/00024382-199406000-00006. PMID: 7537618

Bennett, T., Mahajan, R.P., March, J.E., Kemp, P.A., and Gardiner, S.M. 2004. Regional and temporal changes in cardiovascular responses to norepinephrine and vasopressin during continuous infusion of lipopolysaccharide in conscious rats. Br. J. Anaesth. 93(3): 400-407. doi: 10.1093/bja/aeh214. PMID: 15220167

Bowton, D.L., Bertels, N.H., Prough, D.S., and Stump, D.A. 1989. Cerebral blood-flow is reduced in patients with sepsis syndrome. Crit. Care Med. 17(5): 399-403. doi: 10.1097/00003246-198905000-00004. PMID: 2495896

Cameron, E.M., Wang, S.Y., Fink, M.P., and Sellke, F.W. 1998. Mesenteric and skeletal muscle microvascular responsiveness in subacute sepsis. Shock, 9(3): 184-192. doi: 10.1097/00024382199803000-00005. PMID: 9525325

da Silva-Santos, J.E., Terluk, M.R., and Assreuy, J. 2002. Differential involvement of guanylate cyclase and potassium channels in nitric oxide-induced hyporesponsiveness to phenylephrine in endotoxemic rats. Shock, 17(1): 70-76. doi: 10.1097/00024382-200201000-00012. PMID:

11795672

de Souza, P., Schulz, R., and da Silva-Santos, J.E. 2015. Matrix metalloproteinase inhibitors prevent sepsis-induced refractoriness to vasoconstrictors in the cecal ligation and puncture model in rats. Eur. J. Pharmacol. 765: 164-170. doi: 10.1016/j.ejphar.2015.08.030. PMID: 26297976

Dellinger, R.P., Levy, M.M., Rhodes, A., Annane, D., Gerlach, H., Opal, S.M., et al. 2013. Surviving sepsis campaign: International guidelines for management of severe sepsis and septic shock: 2012. Crit. Care Med. 41(2): 580-637. doi: 10.1097/CCM.0b013e31827e83af. PMID: 23353941 
Doerschug, K.C., Delsing, A.S., Schmidt, G.A., and Ashare, A. 2010. Renin-angiotensin system activation correlates with microvascular dysfunction in a prospective cohort study of clinical sepsis. Crit. Care, 14(1): R24. doi: 10.1186/cc8887. PMID: 20175923

Ellender, T.J., and Skinner, J.C. 2008. The use of vasopressors and inotropes in the emergency medical treatment of shock. Emerg. Med. Clin. North. Am. 26(3): 759-786, ix. doi: 10.1016/j.emc.2008.04.001. PMID: 18655944

Fernandes, D., and Assreuy, J. 2008. Nitric oxide and vascular reactivity in sepsis. Shock, 30: 10-13. doi: 10.1097/SHK.0b013e3181818518. PMID: 18704016

Gunnett, C.A., Berg, D.J., Faraci, F.M., and Feuerstein, G. 1999. Vascular effects of lipopolysaccharide are enhanced in interleukin-10-deficient mice. Stroke, 30(10): 2191-2195; discussion 2195-2196. PMID: 10512928

Hilgenfeldt, U., Kienapfel, G., Kellermann, W., Schott, R., and Schmidt, M. 1987. Reninangiotensin system in sepsis. Clin. Exper. Hypertens. 9(8-9): 1493-1504. doi:

10.3109/10641968709158998. PMID: 2820628

Hiltebrand, L.B., Krejci, V., Jakob, S.M., Takala, J., and Sigurdsson, G.H. 2007. Effects of vasopressin on microcirculatory blood flow in the gastrointestinal tract in anesthetized pigs in septic shock. Anesthesiology, 106(6): 1156-1167. doi: 10.1097/01.anes.0000267599.02140.86. PMID: 17525591

Holmes, C.L., Walley, K.R., Chittock, D.R., Lehman, T., and Russell, J.A. 2001. The effects of vasopressin on hemodynamics and renal function in severe septic shock: a case series. Intens. Care Med. 27(8): 1416-1421. doi: 10.1007/s001340101014. PMID: 11511958 Isakson, P.C., Shofer, F., McKnight, R.C., Feldhaus, R.A., Raz, A., and Needleman, P. 1977. Prostaglandins and the renin-angiotensin system in canine endotoxemia. J. Pharmacol. Exp. Ther. 200(3): 614-622. PMID: 850131 
Kimmoun, A., Ducrocq, N., and Levy, B. 2013. Mechanisms of vascular hyporesponsiveness in septic shock. Curr. Vasc. Pharmacol. 11(2): 139-149. doi: 10.2174/157016113805290245.

PMID: 23506493

Krejci, V., Hiltebrand, L.B., and Sigurdsson, G.H. 2006. Effects of epinephrine, norepinephrine, and phenylephrine on microcirculatory blood flow in the gastrointestinal tract in sepsis. Crit. Care Med. 34(5): 1456-1463. doi: 10.1097/01.CCM.0000215834.48023.57. PMID: 16557162 Landry, D.W., and Oliver, J.A. 2001. Mechanisms of disease: The pathogenesis of vasodilatory shock. N. Engl. J. Med. 345(8): 588-595. PMID: 11529214

Li, T., Croce, K., and Winquist, R.J. 1992. Regional differences in the effects of septic shock on vascular reactivity in the rabbit. J. Pharmacol. Exp. Ther. 261(3): 959-963. PMID: 1602401 Martin, C.M., Yaghi, A., Sibbald, W.J., McCormack, D., and Paterson, N.A. 1993. Differential impairment of vascular reactivity of small pulmonary and systemic arteries in hyperdynamic sepsis. Am. Rev. Respir. Dis. 148(1): 164-172. doi: 10.1164/ajrccm/148.1.164. PMID: 8317793 Mastrangelo, D., Frossard, J.L., Hadengue, A., and Pastor, C.M. 2000. Sepsis decreases the spontaneous and agonist-induced contractile activities in the rat portal vein. J. Hepatol. 33(6): 933-940. doi: 10.1016/S0168-8278(00)80125-7. PMID: 11131455

McGregor, D.D. 1965. The effect of sympathetic nerve stimulation of vasoconstrictor responses in perfused mesenteric blood vessels of the rat. J. Physiol. (Lond.) 177: 21-30. doi: 10.1113/jphysiol.1965.sp007572. PMID: 14296957

Meyer, J.S., Yoshida, K., and Sakamoto, K. 1967. Autonomic control of cerebral blood flow measured by electromagnetic flowmeters. Neurology, 17(7): 638-648. doi:

10.1212/WNL.17.7.638. PMID: 4961274

Papadopoulos, M.C., Davies, D.C., Moss, R.F., Tighe, D., and Bennett, E.D. 2000.

Pathophysiology of septic encephalopathy: a review. Crit. Care Med. 28(8): 3019-3024. doi: 10.1097/00003246-200008000-00057. PMID: 10966289 
Paul, M., Poyan Mehr, A., and Kreutz, R. 2006. Physiology of local renin-angiotensin systems. Physiol. Rev. 86(3): 747-803. doi: 10.1152/physrev.00036.2005. PMID: 16816138

Revelly, J.P., Liaudet, L., Frascarolo, P., Joseph, J.M., Martinet, O., and Markert, M. 2000.

Effects of norepinephrine on the distribution of intestinal blood flow and tissue adenosine triphosphate content in endotoxic shock. Crit. Care Med. 28(7): 2500-2506. doi:

10.1097/00003246-200007000-00052. PMID: 10921585

Rittirsch, D., Huber-Lang, M.S., Flierl, M.A., and Ward, P.A. 2009. Immunodesign of experimental sepsis by cecal ligation and puncture. Nat. Protoc. 4(1): 31-36. doi:

10.1038/nprot.2008.214. PMID: 19131954

Schaller, M.D., Waeber, B., Nussberger, J., and Brunner, H.R. 1985. Angiotensin II, vasopressin, and sympathetic activity in conscious rats with endotoxemia. Am. J. Physiol. 249(6 Pt 2): H1086-1092. PMID: 3907375

Suba, E.A., McKenna, T.M., and Williams, T.J. 1992. Differential contractile responses of mesenteric and pulmonary artery segments to norepinephrine and phorbol ester in the septic pig. Circ. Shock, 37(2): 164-168. PMID: 1511508

Takakura, K., Xiaohong, W., Takeuchi, K., Yasuda, Y., and Fukuda, S. 2003. Deactivation of norepinephrine by peroxynitrite as a new pathogenesis in the hypotension of septic shock. Anesthesiology, 98(4): 928-934. doi: 10.1097/00000542-200304000-00020. PMID: 12657855 Tsuneyoshi, I., Yamada, H., Kakihana, Y., Nakamura, M., Nakano, Y., and Boyle, W.A. 2001. Hemodynamic and metabolic effects of low-dose vasopressin infusions in vasodilatory septic shock. Crit. Care Med. 29(3): 487-493. doi: 10.1097/00003246-200103000-00004. PMID: 11373409

Zhang, W., Chen, X., Huang, L., Lu, N., Zhou, L., Wu, G., and Chen, Y. 2014. Severe sepsis: Low expression of the renin-angiotensin system is associated with poor prognosis. Exp. Ther. Med. 7(5): 1342-1348. doi: 10.3892/etm.2014.1566. PMID: 24940436 


\section{Figure Captions}

Fig. 1. Unaltered $\mathrm{KCl}$ reactivity of vessels from CLP-subjected rats. The increase in the vascular tone induced by $120 \mathrm{mM} \mathrm{KCl}$ modified PSS was recorded in mesenteric (A), renal (B), carotid (C) and tail (D) arteries from non-septic (sham) and CLP groups at $6 \mathrm{~h}$ and $18 \mathrm{~h}$ after the surgery. The values show the mean \pm standard error of the mean of 6 preparations per group.

Fig. 2. Mesenteric arteries from CLP-subjected rats present reduced reactivity to phenylephrine and angiotensin II, but normal reactivity to norepinephrine and vasopressin. Concentration response curves to phenylephrine (A), norepinephrine (B), angiotensin II (C), and vasopressin (D) were determined in mesenteric arteries obtained from non-septic (sham) and CLP groups at 6 and $18 \mathrm{~h}$ after the surgery. The values show the mean \pm standard error of the mean of 5-9 preparations per group. * indicates $p<0.05$ compared with the sham group; \# indicates $p<0.05$ compared with the CLP $6 \mathrm{~h}$ group.

Fig. 3. Lack of changes in vascular reactivity to vasoconstrictors in renal arteries from CLPsubjected rats. Concentration response curves to phenylephrine (A), norepinephrine (B), angiotensin II (C), and vasopressin (D) were determined in renal arteries obtained from nonseptic (sham) and CLP groups at 6 and $18 \mathrm{~h}$ after surgery. The values show the mean \pm standard error of the mean of 5-9 preparations per group.

Fig. 4. Reduced vascular reactivity to vasoconstrictors in carotid arteries from CLP-subjected rats. Concentration response curves to phenylephrine (A), norepinephrine (B), angiotensin II (C), and vasopressin (D) were determined in carotid arteries obtained from non-septic (sham) and CLP groups at 6 and $18 \mathrm{~h}$ after surgery. The values show the mean \pm standard error of the 
mean of 5-7 preparations per group. * indicates $p<0.05$ compared with the sham group; \# indicates $p<0.05$ compared with CLP 6 h group.

Fig. 5. Tail arteries from CLP-subjected rats present reduced responses to phenylephrine but are hyperreactive to norepinephrine and vasopressin. Concentration response curves to phenylephrine (A), norepinephrine (B), angiotensin II (C), and vasopressin (D) were determined in tail arteries obtained from non-septic (sham) and CLP groups at 6 and $18 \mathrm{~h}$ after the surgery. The values show the mean \pm standard error of the mean of 5-7 preparations per group. * indicates $p<0.05$ compared with the sham group; $\S$ indicates $p<0.05$ compared with the CLP 6 $\mathrm{h}$ group.

Fig. 6. The mesenteric vascular bed from CLP-subjected rats shows reduced responses to phenylephrine, norepinephrine and angiotensin II, but normal or increased reactivity to vasopressin. Dose response curves to phenylephrine (A), norepinephrine (B), angiotensin II (C), and vasopressin (D) were obtained in perfused mesenteric arteries from non-septic (sham) and CLP groups at 6 and $18 \mathrm{~h}$ after the surgery. The values show the mean \pm standard error of the mean of 6 preparations per group. * indicates $p<0.05$ compared with the sham group. 
Table 1. Vascular reactivity of superior mesenteric arteries from non-septic and CLP-subjected rats for vasoactive agents.

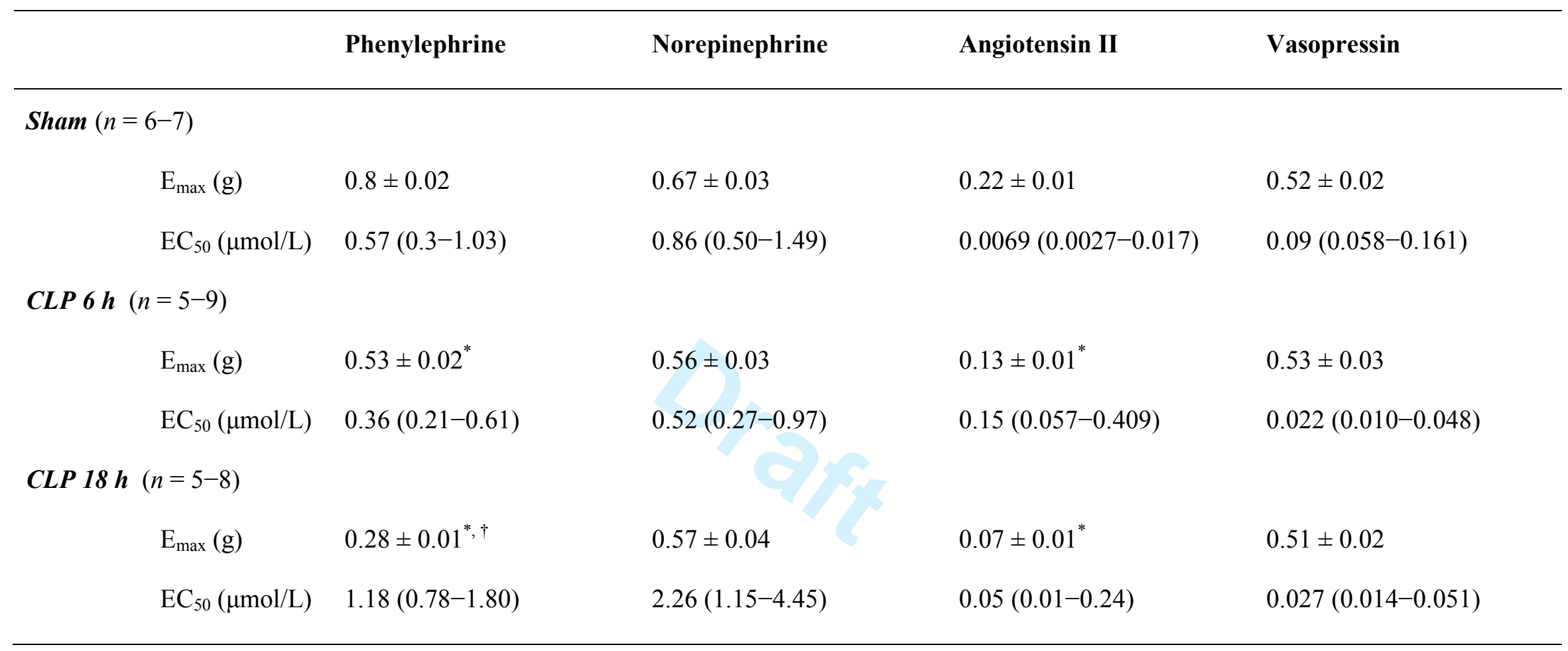

$\mathrm{E}_{\max }=$ Maximum contractile effect. $\mathrm{EC}_{50}=$ half maximum effective concentration. The mesenteric arteries were obtained from sham (nonseptic), or CLP-subjected rats at $6 \mathrm{~h}$ or $18 \mathrm{~h}$ after surgery, and their reactivity to cumulative concentrations of vasoactive agents was evaluated in organ baths (for details see the Methods section). The values show the mean \pm standard error mean (for $\mathrm{E}_{\max }$ ), or the mean and the $95 \%$ confidence interval (for $\mathrm{EC}_{50}$ ). Statistical analyses were performed through two-way ANOVA followed by Tukey's multiple comparison test.

${ }^{*}$ indicates $p<0.05$ compared with the sham (non-septic) group tested for the same vasoconstrictor (same column). ${ }^{\dagger}$ indicates $p<0.05$ compared with the CLP $6 \mathrm{~h}$ group challenged with the same vasoconstrictor (same column). 
Table 2. Vascular reactivity of renal arteries from non-septic and CLP-subjected rats to vasoactive agents.

\begin{tabular}{|c|c|c|c|c|}
\hline & Phenylephrine & Norepinephrine & Angiotensin II & Vasopressin \\
\hline \multicolumn{5}{|l|}{ Sham $(n=5-8)$} \\
\hline $\mathrm{EC}_{50}(\mu \mathrm{mol} / \mathrm{L})$ & $0.27(0.17-0.42)$ & $0.31(0.20-0.48)$ & $0.014(0.0014-0.13)$ & $0.016(0.011-0.023)$ \\
\hline \multicolumn{5}{|l|}{ CLP $6 \boldsymbol{h}(n=5-7)$} \\
\hline $\mathrm{E}_{\max }(\mathrm{g})$ & $1.24 \pm 0.04$ & $0.95 \pm 0.08$ & $0.13 \pm 0.02$ & $0.89 \pm 0.03$ \\
\hline $\mathrm{EC}_{50}(\mu \mathrm{mol} / \mathrm{L})$ & $0.28(0.17-0.45)$ & $0.48(0.020-1.13)$ & $0.013(0.0013-0.13)$ & $0.015(0.0082-0.030)$ \\
\hline \multicolumn{5}{|l|}{ CLP $18 h(n=5-9)$} \\
\hline $\mathrm{EC}_{50}(\mu \mathrm{mol} / \mathrm{L})$ & $0.72(0.47-1.12)$ & $0.21(0.07-0.57)$ & $0.08(0.018-0.41)$ & $0.013(0.0073-0.025)$ \\
\hline
\end{tabular}

$\mathrm{E}_{\max }=$ Maximum contractile effect. $\mathrm{EC}_{50}=$ half maximum effective concentration. The renal arteries were obtained from sham (non-septic), or CLP-subjected rats at $6 \mathrm{~h}$ or $18 \mathrm{~h}$ after surgery, and their reactivity to cumulative concentrations of vasoactive agents evaluated in organ baths (for details see the Methods section). The values show the mean \pm standard error mean (for $\mathrm{E}_{\max }$ ), or the mean and the $95 \%$ confidence interval (for $\mathrm{EC}_{50}$ ). Statistical analyses were performed through two-way ANOVA followed by Tukey's multiple comparison test. No statistical differences were found when the effects of the same vasoactive agent were compared among the groups (same column). 
Table 3. Vascular reactivity of carotid arteries from non-septic and CLP-subjected rats to vasoactive agents.

\begin{tabular}{|c|c|c|c|c|}
\hline & Phenylephrine & Norepinephrine & Angiotensin II & Vasopressin \\
\hline \multicolumn{5}{|l|}{ Sham $(n=5-7)$} \\
\hline $\mathrm{E}_{\max }(\mathrm{g})$ & $0.27 \pm 0.01$ & $0.25 \pm 0.01$ & $0.32 \pm 0.01$ & $0.11 \pm 0.008$ \\
\hline $\mathrm{EC}_{50}(\mu \mathrm{mol} / \mathrm{L})$ & $0.062(0.032-0.12)$ & $0.041(0.02-0.07)$ & $0.017(0.007-0.04)$ & $0.13(0.06-0.24)$ \\
\hline \multicolumn{5}{|l|}{ CLP $6 \boldsymbol{h}(n=5-7)$} \\
\hline $\mathrm{E}_{\max }(\mathrm{g})$ & $0.19 \pm 0.01^{*}$ & $0.12 \pm 0.009^{*}$ & $0.30 \pm 0.02$ & $0.08 \pm 0.004$ \\
\hline $\mathrm{EC}_{50}(\mu \mathrm{mol} / \mathrm{L})$ & $0.058(0.029-0.11)$ & $0.034(0.01-0.09)$ & $0.083(0.03-0.17)$ & $0.046(0.02-0.07)$ \\
\hline \multicolumn{5}{|l|}{ CLP $18 \mathrm{~h}(n=5-7)$} \\
\hline $\mathrm{E}_{\max }(\mathrm{g})$ & $0.12 \pm 0.007^{* \dagger}$ & $0.15 \pm 0.01^{*}$ & $0.15 \pm 0.01^{*}, \dagger$ & $0.05 \pm 0.007^{*}$ \\
\hline $\mathrm{EC}_{50}(\mu \mathrm{mol} / \mathrm{L})$ & $0.044(0.020-0.09)$ & $0.049(0.01-0.13)$ & $0.11(0.02-0.42)$ & $0.07(0.01-0.36)$ \\
\hline
\end{tabular}

$\mathrm{E}_{\max }=$ Maximum contractile effect. $\mathrm{EC}_{50}=$ half maximum effective concentration. The carotid arteries were obtained from sham (non-septic), or CLP-subjected rats at $6 \mathrm{~h}$ or $18 \mathrm{~h}$ after surgery, and their reactivity to cumulative concentrations of vasoactive agents was evaluated in organ baths (for details see the Methods section). The values show the mean \pm standard error mean (for $\mathrm{E}_{\max }$ ), or the mean and the $95 \%$ confidence interval (for $\mathrm{EC}_{50}$ ). Statistical analyses were performed through two-way ANOVA followed by Tukey's multiple comparison test. ${ }^{*}$ indicates $p<$ 0.05 compared with the sham (non-septic) group tested for the same vasoconstrictor (same column). ${ }^{\dagger}$ indicates $p<0.05$ compared with the CLP $6 \mathrm{~h}$ group tested for the same vasoconstrictor (same column). 
Table 4. Vascular reactivity of tail arteries from non-septic and CLP-subjected rats to vasoactive agents.

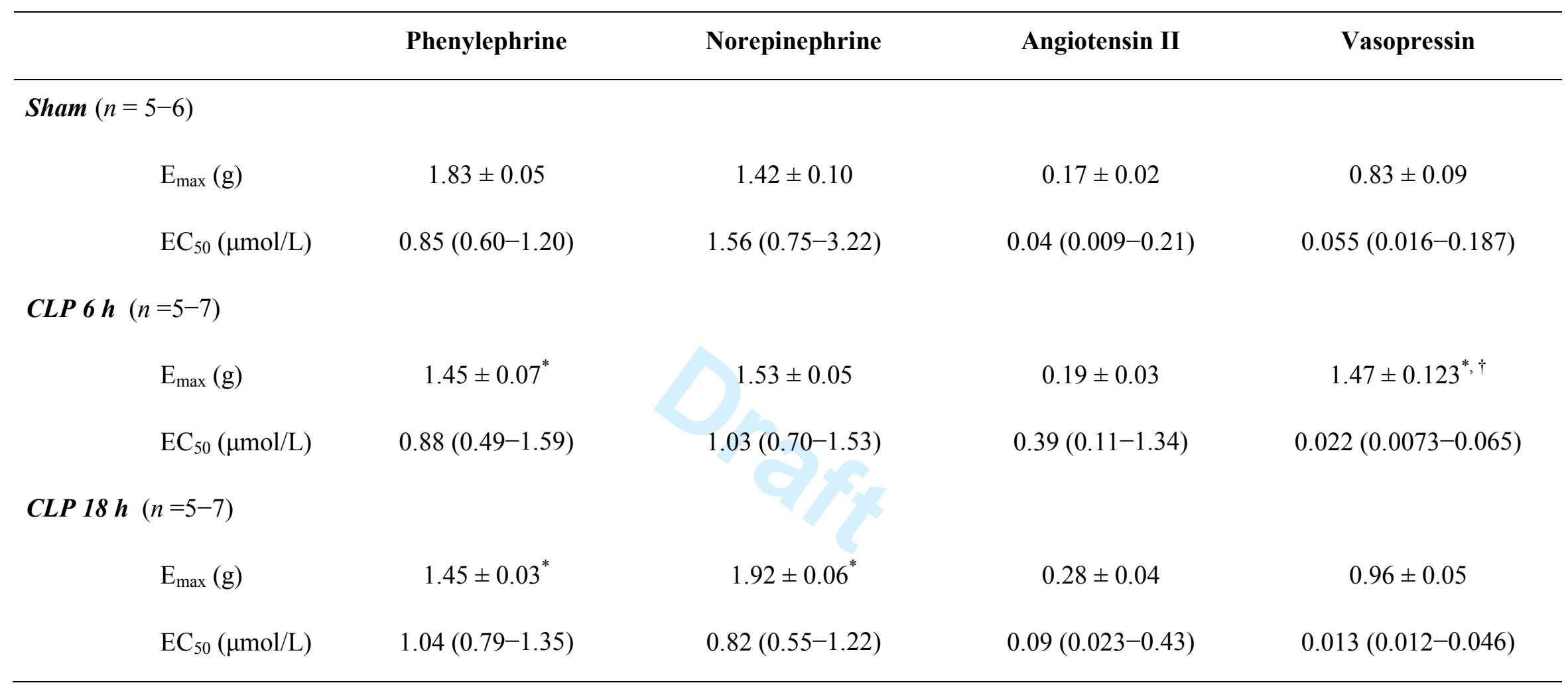

$\mathrm{E}_{\max }=$ Maximum contractile effect. $\mathrm{EC}_{50}=$ half maximum effective concentration. The tail arteries were obtained from sham (non-septic), or CLP-subjected rats at $6 \mathrm{~h}$ or $18 \mathrm{~h}$ after surgery, and their reactivity to cumulative concentrations of vasoactive agents was evaluated in organ baths (for details see the Methods section). The values show the mean \pm standard error mean (for $\mathrm{E}_{\max }$ ), or the mean and the $95 \%$ confidence interval (for $\mathrm{EC}_{50}$ ). Statistical analyses were performed through two-way ANOVA followed by Tukey's multiple comparison test. ${ }^{*}$ indicates $p<$ 0.05 compared with the sham (non-septic) group tested for the same vasoconstrictor (same column). ${ }^{\dagger}$ indicates $p<0.05$ compared with the CLP $18 \mathrm{~h}$ group tested for the same vasoconstrictor (same column). 

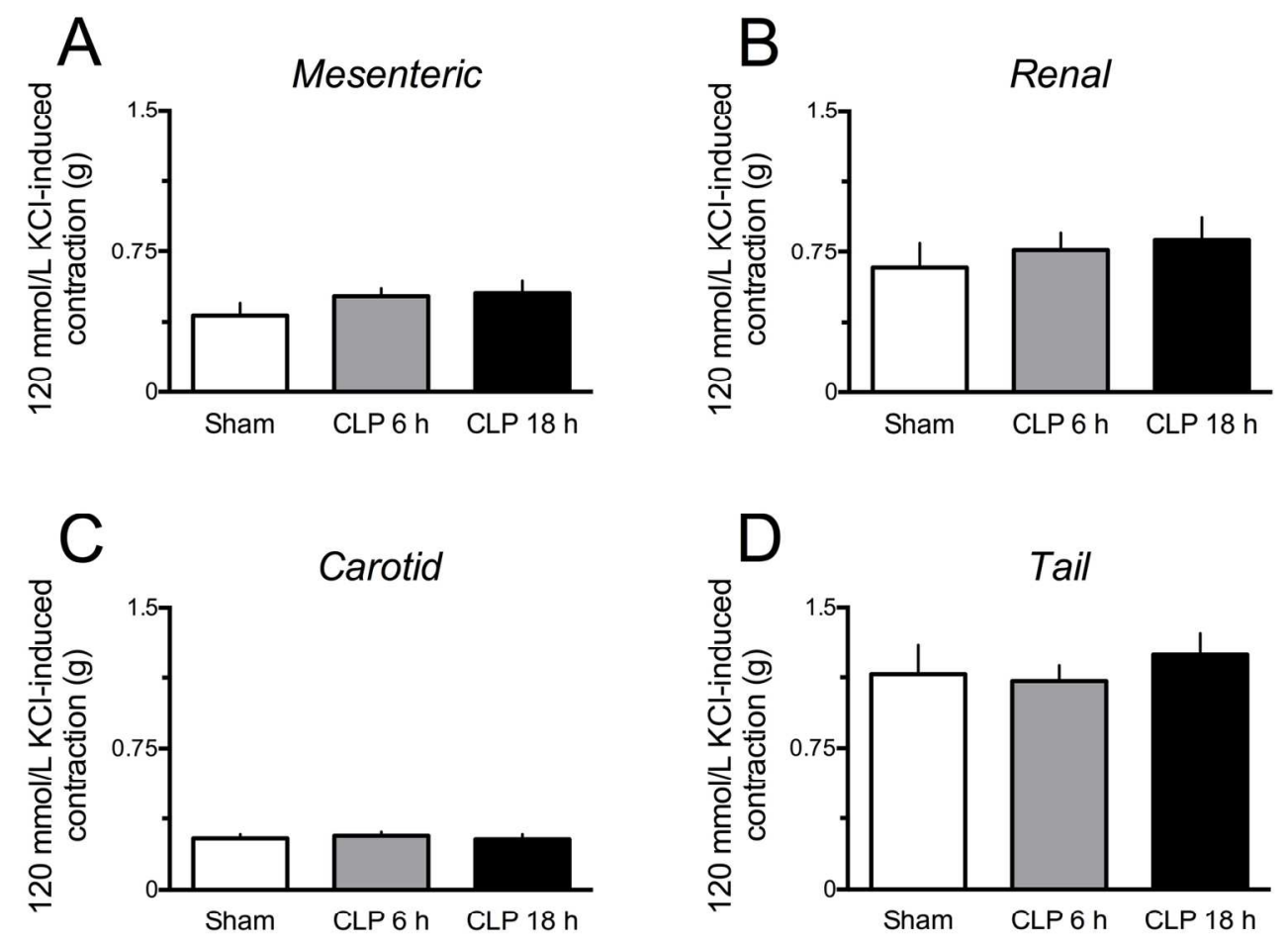

Figure 1

Bernardelli et al.

Figure 1.

$150 \times 140 \mathrm{~mm}(300 \times 300$ DPI $)$ 


\section{Superior Mesenteric Artery}
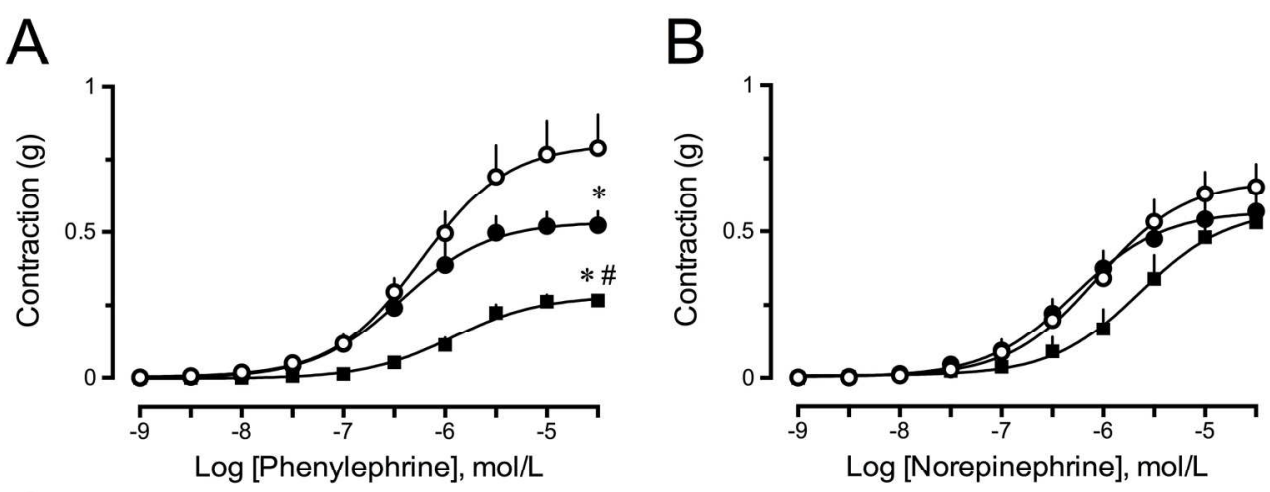

C

D
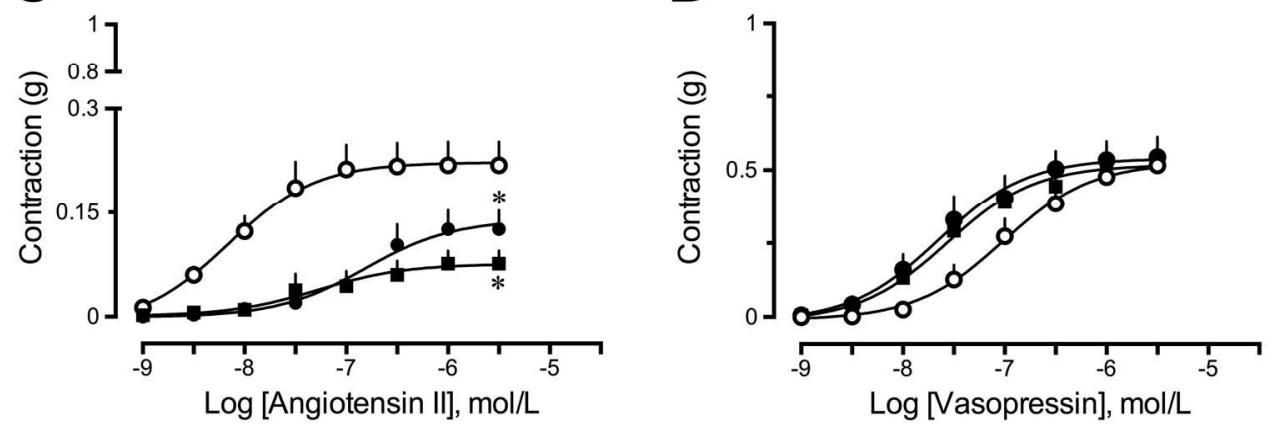

-o- Sham

- CLP $6 \mathrm{~h}$

$\rightarrow$ CLP $18 \mathrm{~h}$

Figure 2

Bernardelli et al.

Figure 2.

$179 \times 189 \mathrm{~mm}(300 \times 300$ DPI $)$ 


\section{Renal Artery}
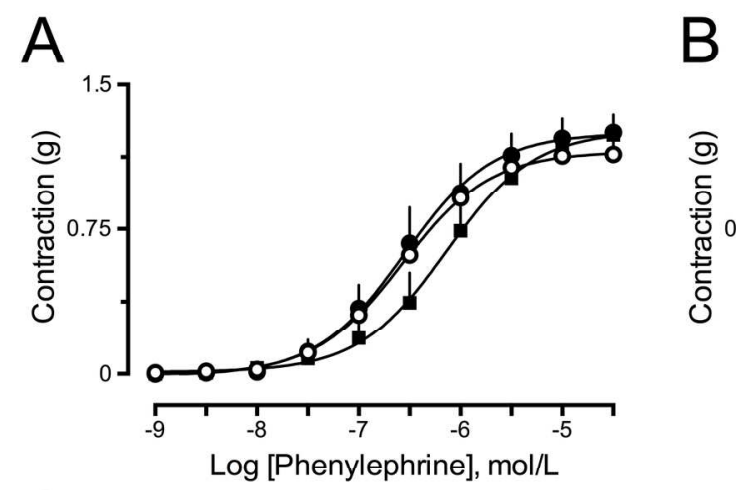

C

$\mathrm{B}$

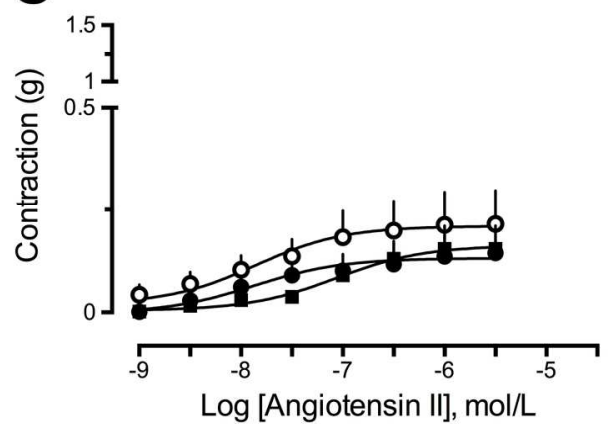

D
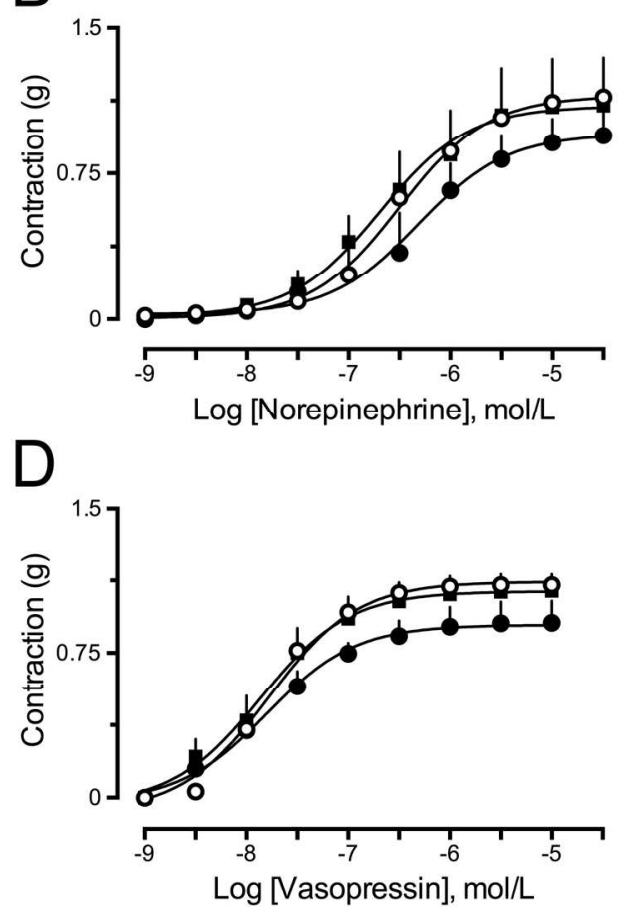

- o- Sham

$\rightarrow$ CLP $6 \mathrm{~h}$

$\rightarrow$ CLP $18 \mathrm{~h}$

Figure 3

Bernardelli et al.

Figure 3.

$179 \times 189 \mathrm{~mm}(300 \times 300 \mathrm{DPI})$ 


\section{Carotid Artery}
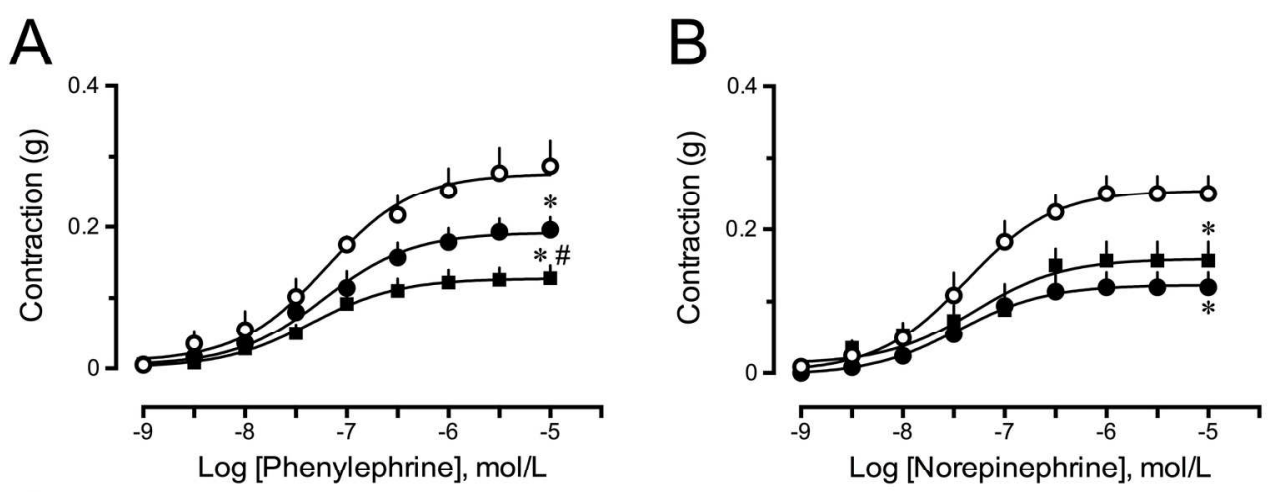

C

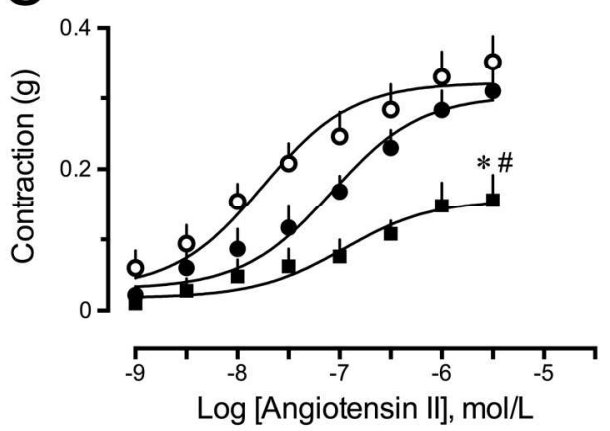

D

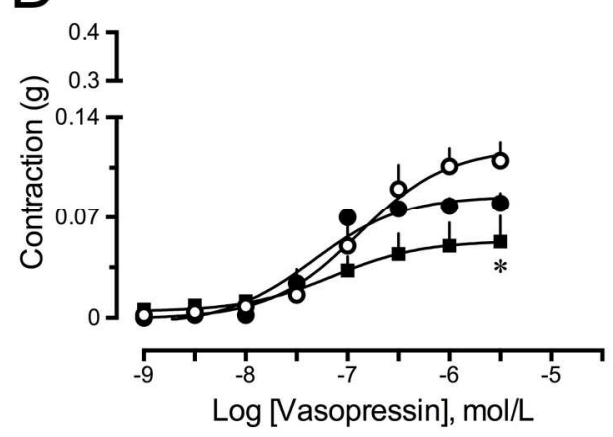

-o- Sham

- CLP $6 \mathrm{~h}$

- CLP $18 \mathrm{~h}$

Figure 4

Bernardelli et al.

Figure 4.

$179 \times 189 \mathrm{~mm}(300 \times 300 \mathrm{DPI})$ 


\section{Tail Artery}

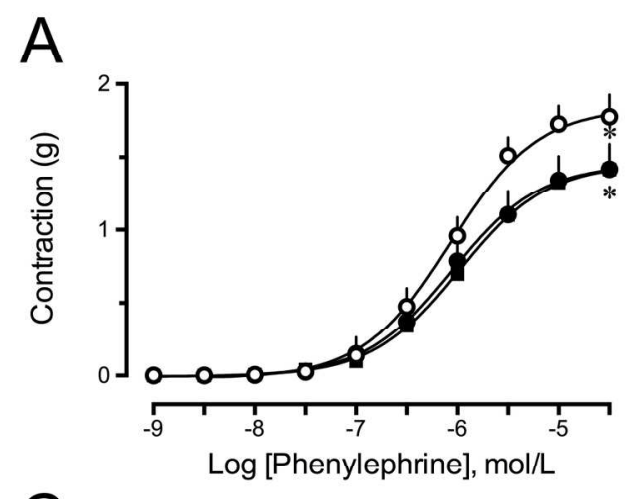

C

$\mathrm{B}$

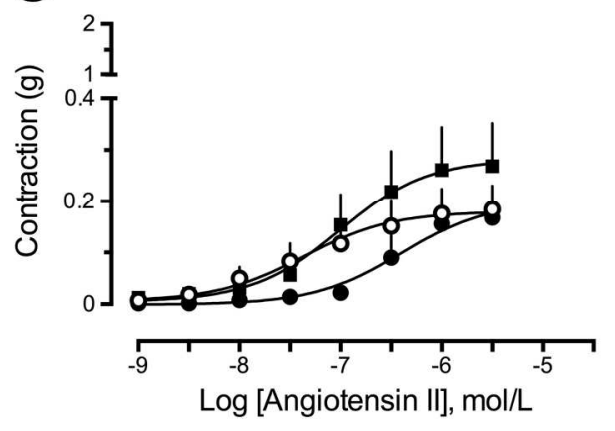

D
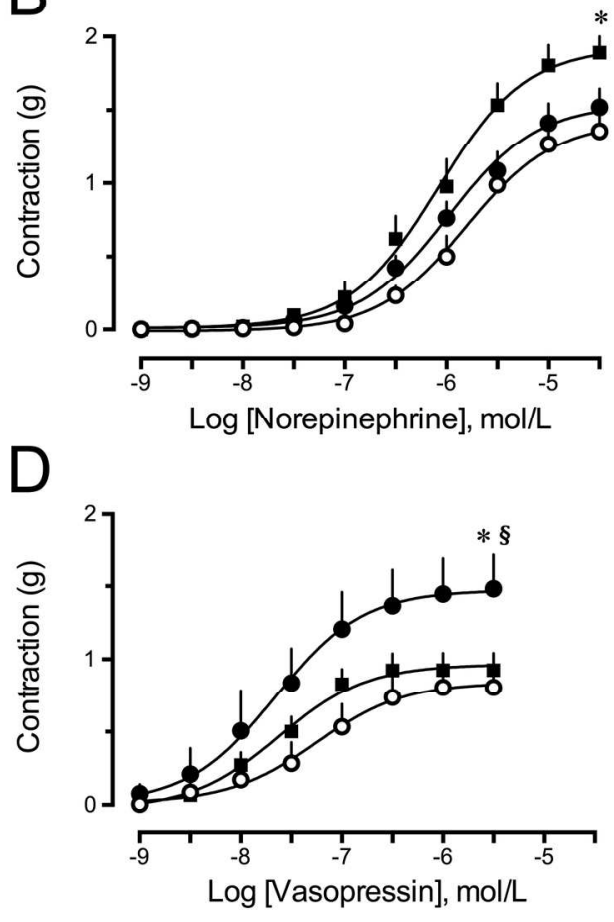

- Sham $\rightarrow$ CLP $6 \mathrm{~h}$

CLP $18 \mathrm{~h}$

Figure 5

Bernardelli et al.

Figure 5.

$179 \times 188 \mathrm{~mm}(300 \times 300 \mathrm{DPI})$ 


\section{Mesenteric Vascular Bed}
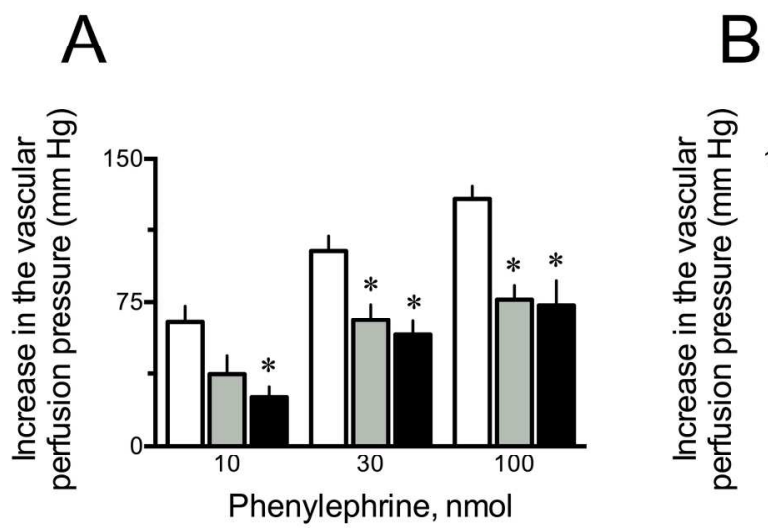

C

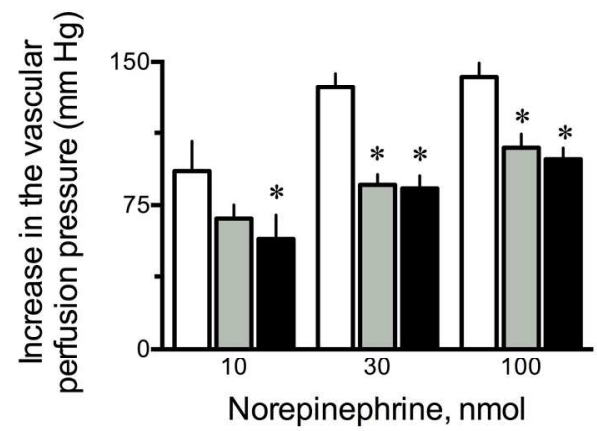

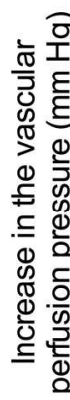

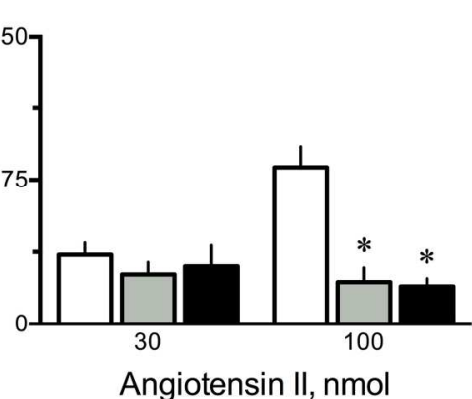

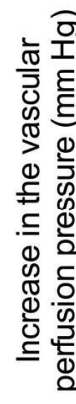

$\mathrm{D}$

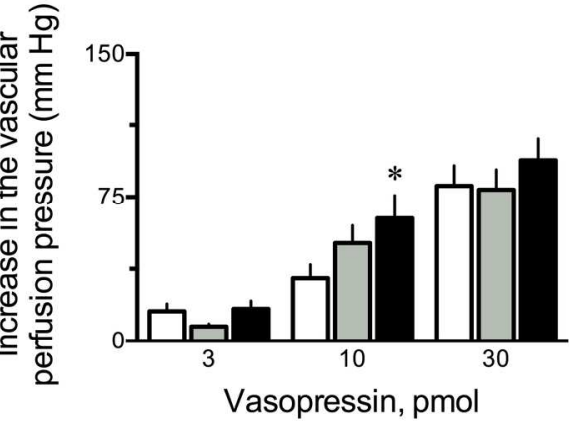

$\square$ Sham $\square$ CLP $6 \mathrm{~h} \quad \square$ CLP $18 \mathrm{~h}$

Figure 6

Bernardelli et al.

Figure 6

$185 \times 213 \mathrm{~mm}(300 \times 300 \mathrm{DPI})$ 